\title{
Interaction between Psychotropic Medications and Alcohol: Perceptions among Patients Attending an Adult Mental Health Day Hospital Program
}

\author{
Cynthia Cheng, Fatima Mithoowani, Thomas Ungar, and Monica Lee
}

\begin{abstract}
Background: Interaction between alcohol and certain medications can lead to adverse consequences. Individuals with mental health disorders are particularly vulnerable because of their psychotropic medications, which are typically taken over extended periods and which are known to have pharmacokinetic and pharmacodynamic interactions with alcohol. It is unknown what education these patients receive from their health care providers and how such interactions are managed.
\end{abstract}

Objectives: To determine whether individuals with mental health disorders are aware of alcohol-drug interactions and if so, how they use such information.

Methods: A questionnaire was developed to explore the perceptions of mental health patients concerning alcohol-drug interactions. The questionnaire included questions in 3 domains: knowledge of potential alcohol-drug interactions, consumption of alcohol while taking psychotropic medications, and source of advice regarding the interactions. Attendees of an adult mental health day hospital program were invited to participate.

Results: A total of 131 participants answered the questionnaire between July 2014 and February 2015; 31 of the questionnaires were incomplete and were excluded from analysis. Of the 100 participants included in the analyses, 75 reported having received counselling from a health care provider about alcohol-drug interactions, and 49 of these reported following the advice provided. The most common advice reported by participants was to avoid alcohol consumption while taking medications. Serious adverse effects, such as worsening of a psychiatric condition, admission to hospital, and increased drowsiness, were reported by 23 participants. Sixty-nine participants considered physicians to be the best source of information about these interactions.

Conclusions: Most participants reported that they had received information about strategies to avoid negative consequences from alcohol-drug interactions. Nevertheless, consumption of alcohol occurred, and almost one-quarter of participants reported a serious adverse effect related to consuming alcohol. These self-reported data indicate that patients do not

\section{RÉSUMÉ}

Contexte : L'interaction entre l'alcool et certains médicaments peut mener à des conséquences cliniques. Les personnes atteintes de troubles mentaux y sont particulièrement vulnérables à cause des médicaments psychotropes qu'ils prennent d'habitude sur une période prolongée et pour lesquels les interactions pharmacocinétiques et pharmacodynamiques avec l'alcool sont notoires. On ne sait pas quels conseils ces patients reçoivent de leurs fournisseurs de soins de santé et comment de telles interactions sont gérées.

Objectifs : Déterminer si les personnes atteintes de troubles mentaux sont conscientes des interactions entre l'alcool et les médicaments et, si oui, dévoiler comment elles agissent à la lumière de cette information.

Méthodes : On a mis au point un questionnaire pour enquêter sur les perceptions qu'ont les patients atteints de troubles mentaux des interactions alcool-médicaments. Les questions y étaient regroupées en trois catégories : conscience des interactions potentielles alcool-médicaments, consommation d'alcool en prenant des psychotropes et source des conseils sur les interactions. Les participants à un programme hospitalier de jour pour adultes atteints de troubles mentaux ont été invités à participer à l'étude. Résultats : Au total, 131 participants ont rempli le questionnaire entre juillet 2014 et février 2015; 31 des questionnaires étaient incomplets et ont été exclus de l'analyse. Parmi les 100 participants inclus dans les analyses, 75 ont indiqué avoir reçu des conseils d'un fournisseur de soins de santé sur les interactions alcool-médicaments et 49 d'entre eux ont affirmé avoir suivi les conseils offerts. Le conseil le plus fréquent selon les répondants était d'éviter la consommation d'alcool lorsqu'on prend des médicaments. De graves réactions indésirables, telles que la détérioration d'un trouble psychiatrique, l'admission à l'hôpital et une somnolence accrue, ont été soulignées par 23 participants. Soixante-neuf participants considéraient les médecins comme les meilleures sources d'information à propos de ces interactions.

Conclusions : La plupart des participants ont indiqué avoir reçu de l'information sur les stratégies permettant d'éviter les conséquences des interactions alcool-médicaments. Certains ont tout de même consommé 
necessarily follow the advice of their health care providers. Future studies should explore reasons for the gap between advice and action and how to minimize it.

Keywords: psychotropic drugs, alcohol, drug-alcohol interactions, perception, questionnaire, mental health

\section{Can J Hosp Pharm. 2018;71(1):7-13}

de l'alcool et près du quart des participants ont signalé une réaction indésirable grave liée à la consommation d'alcool. Ces données autodéclarées révèlent que les patients ne suivent pas nécessairement les conseils de leurs fournisseurs de soins de santé. Des études ultérieures devraient se pencher sur les raisons expliquant l'écart entre les conseils et les actions et sur les solutions pour réduire cet écart.

Mots clés : médicaments psychotropes, alcool, interactions médicamentalcool, perception, questionnaire, santé mentale

\section{INTRODUCTION}

A ccording to a Canadian study published in $2012,80 \%$ of males and $74 \%$ of females aged 15 years or older reported consuming alcohol within the past year (data for 2010). ${ }^{1}$ Alcohol interacts with many over-the-counter and prescription drugs, including psychotropic medications such as antidepressants, anxiolytics, and antipsychotics, which are commonly prescribed for the treatment of mental health disorders. The mechanism by which alcohol interacts with medications can be pharmacokinetic or pharmacodynamic in nature. Acute alcohol ingestion may inhibit the enzymes responsible for drug metabolism, increasing the risk of adverse effects from a medication by prolonging and enhancing its availability. Conversely, chronic alcohol ingestion may induce certain enzymes, resulting in enhanced drug elimination and diminished therapeutic effects. Medications can also alter the metabolism of alcohol, increase alcohol-related adverse effects, and lower the threshold for intoxication. When combined with psychotropic medications, alcohol may potentiate the drugs' inhibitory effects on the central nervous system, which can impair an individual's ability to function. ${ }^{2}$ It has been estimated that alcohol-medication interactions may be a factor in at least $25 \%$ of all emergency room visits. ${ }^{3}$

Several studies have evaluated patterns of use of alcohol and interacting medications in various populations. ${ }^{4-7}$ In a populationbased study in the United States, Breslow and others ${ }^{8}$ found that $41.5 \%$ of adult current drinkers used alcohol-interactive medications, the most commonly used medication classes being cardiovascular agents and central nervous system agents. Although literature about the interactions between psychotropic medications and alcohol in Canada is sparse, one Canadian study reported the prevalence of heavy alcohol consumption among benzodiazepine users in the previous week as $7.2 \%$; current benzodiazepine users were less likely than non-current users to have recently consumed any alcohol. ${ }^{9}$ Psychotropic medications are often prescribed for long-term treatment of chronic mental health conditions; as such, it is important for patients to understand the serious negative consequences and risks that may result from alcohol-drug interactions. Health care professionals, such as physicians, nurses, and pharmacists, may give patients information related to their medications. However, it is unknown whether patients are aware of potential interactions with alcohol or whether they follow any advice that is provided.

The goal of this study was to explore the knowledge of and perceptions about alcohol-drug interactions among individuals attending the Adult Mental Health Day Hospital Program at North York General Hospital, in Toronto, Ontario. This was a baseline study, with participants being asked to complete the study survey before any interaction with the program's clinicians.

\section{METHODS}

\section{Questionnaire}

A literature search was conducted to determine whether a similar validated survey existed to help answer the research questions. No prior studies on this topic were found, so the authors developed a self-administered questionnaire to investigate patients' knowledge about and specific advice received regarding alcohol intake while using prescription medications. The questionnaire was developed through consensus among 3 of the authors (C.C., F.M., M.L.). Questions were formulated on the basis of what the authors thought would best answer the research questions. The questionnaire was then distributed to 5 non-health care professionals, who evaluated readability of the content, layout, and style. Feedback was incorporated to improve readability of the questions. However, the questionnaire was not pretested with individuals similar to those in the intended study sample, and it has not been validated.

The questionnaire consisted of a section concerning demographic characteristics and an additional 9 questions addressing the following 3 domains: knowledge of drug-alcohol interactions, consumption of alcohol while taking psychotropic medications, and source of advice regarding alcohol-drug interactions. The complete questionnaire is available in Appendix 1 
(https://www.cjhp-online.ca/index.php/cjhp/issue/view/125/ showToc). A convenience sample of 100 acceptable surveys was chosen.

\section{Participant Selection}

Individuals newly enrolled in the Adult Mental Health Day Hospital Program (referred to hereafter as "the Day Hospital Program") at North York General Hospital were invited to complete the questionnaire. One component of the program involves pharmacy teachings, which include discussions of alcohol use. Therefore, patients who had previously been enrolled in the program, as well as current program enrollees, were excluded, to avoid study participation by patients with knowledge gained through program experience.

The Day Hospital Program is a 3-week outpatient program that was developed as an alternative to traditional inpatient treatment for those not requiring inpatient care and as a transitional "step-down" program for patients with subacute conditions. The program provides assessment and treatment services and promotes recovery. Those eligible for the program are adults 18 years of age or older who, in the clinical judgement of the referring physician (family practice physician or psychiatrist), are in acute emotional distress and require immediate and intensive intervention, yet have sufficient support to continue living in the community. ${ }^{10}$ Patients who have recently been discharged from a hospital are also eligible. There is no specific timeframe used to define a "recent discharge"; eligible inpatients usually receive a referral during the hospital stay and are placed on a waitlist.

Within the Day Hospital Program, patients have the opportunity to work with an interdisciplinary team to learn about symptom management, treatment modalities, and coping skills, and to receive care for stabilization and treatment of their mental health condition. At the time of this study, the interdisciplinary team consisted of an occupational therapist, a social worker, psychiatrists (including T.U.), a psychologist, nurses, and pharmacists (C.C., F.M.). Among other activities, patients participate in twice-weekly group medication education sessions conducted by pharmacists, which include a brief discussion of alcohol use while taking psychotropic medications. The Day Hospital population was selected for this study because its participants represent a cohort transitioning toward outpatient management of their mental health conditions. They have more contact with health care providers than do outpatients not enrolled in this type of program, and can provide insight into perceptions and knowledge of drug-alcohol interactions.

\section{Data Collection}

The introduction letter and questionnaire were included in the orientation package that patients received from the unit secretary on their first day of the Day Hospital Program, before contact with any health care professional (including the program's pharmacists). Each patient was given an hour to complete the orientation package and was given the choice of completing the anonymous questionnaire for this study. Questionnaires were collected by the unit secretary and placed in a tamper-resistant box. Incomplete questionnaires (those with 3 or more questions left unanswered) were excluded from the analysis. All responses were entered into a spreadsheet (Excel 2010, Microsoft Corporation, Redmond, Washington) by one investigator (C.C.). A second investigator (F.M.) verified the data entry for accuracy. Descriptive statistics were used to summarize the data. Written consent was not requested, because completion of the anonymous survey was deemed to imply consent to participate in the study. The research protocol was reviewed and approved by the North York General Hospital Research Ethics Board in June 2014.

\section{RESULTS}

Over the 8-month study period (July 2014 to February 2015), all 506 patients who were newly admitted to the Day Hospital Program were invited to participate in the study. Of 131 surveys submitted, 31 were incomplete and were therefore excluded from analysis; therefore, 100 surveys were included in the analysis.

\section{Demographic and Clinical Characteristics}

The study sample consisted of 46 male participants, 52 female participants, and 2 participants who did not disclose their sex. Fifty-eight of the 100 respondents were 39 years of age or younger. Eighty-eight had taken at least one psychotropic medication, with antidepressants and benzodiazepines being the

\section{Table 1. Characteristics of Participants}

\begin{tabular}{lc} 
Characteristic & $\begin{array}{c}\text { No. of Participants } \\
(\boldsymbol{n}=\mathbf{1 0 0 )}\end{array}$ \\
\hline Age (years) & 33 \\
$18-29$ & 25 \\
$30-39$ & 15 \\
$40-49$ & 16 \\
$50-59$ & 8 \\
$60-69$ & 3 \\
Did not disclose & 46 \\
\hline Sex & 52 \\
Men & 2 \\
Women & \\
Did not disclose & 42 \\
\hline Medications taken* & 46 \\
Benzodiazepines & 24 \\
Antidepressants & 22 \\
Antipsychotics & 3 \\
Mood stabilizers & 12 \\
Stimulants & \\
None & *Some participants reported taking more than one type of medication.
\end{tabular}


most common (Table 1). Nine participants indicated that they had previously required an intervention for alcohol misuse, and 14 stated that alcohol has been a factor in past hospital admissions. Figure 1 depicts the current alcohol consumption reported by the participants. Of the 100 respondents, most (87) reported consuming alcohol once a week or less frequently.

\section{Knowledge of Drug-Alcohol Interaction}

Seventy-five of the respondents acknowledged that they had received advice about taking psychotropic medications and drinking alcohol (Figure 2). Fifty-six (75\%) of these 75 respondents reported that the information they had received was sufficient, and $8(11 \%)$ indicated that the information was not sufficient. Only 49 (65\%) of the 75 stated that they had followed the advice

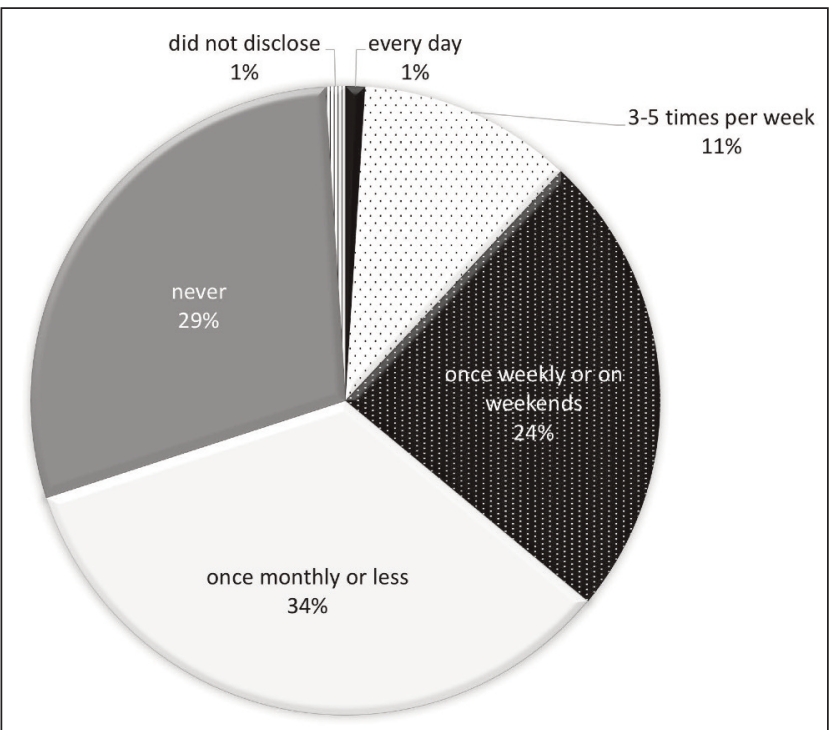

Figure 1. Reported frequency of current alcohol consumption among the 100 survey respondents. received. The most common advice received was to avoid alcohol consumption while on medications ( 49 of 75 [65\%]), followed by limiting the number of alcoholic drinks (19 of 75 [25\%]) (Figure 3).

\section{Consumption of Alcohol while Taking Psychotropic Medications}

Twenty-three respondents reported experiencing a serious adverse effect related to an interaction between their psychotropic medication and alcohol, specifically hospital admission $(n=5)$, worsening of their psychiatric condition $(n=7)$, and increase in drowsiness $(n=11)$ (Figure 4). Of these 23 respondents, 21 had received counselling regarding psychotropic medication use and alcohol consumption, although the questionnaire did not explore whether the counselling was received before or after the selfreported adverse effects. When asked whether they had considered the possibility of an alcohol-drug interaction before consuming alcohol, 33 of the 100 participants reported having thought about the interaction, and 14 reported a decision to deal with the consequences afterward. Three 3 respondents selected both of these options; by consensus, the authors assumed the worst scenario and counted these respondents only in the second category ("deal with the consequences").

\section{Source of Advice Regarding Alcohol-Drug Interactions}

Participants were asked to indicate all sources from which they had obtained information about alcohol-drug interactions (Figure 5, top). Family doctors, psychiatrists, and pharmacists were the most frequently identified sources of the interaction information, followed by the internet. Friends, family, and addiction counsellors were less commonly identified sources. With respect to which health care professionals were considered best to discuss alcohol use and psychotropic medications, psychiatrists ranked first and family doctors second, followed by addiction counsellors and pharmacists (Figure 5, bottom).

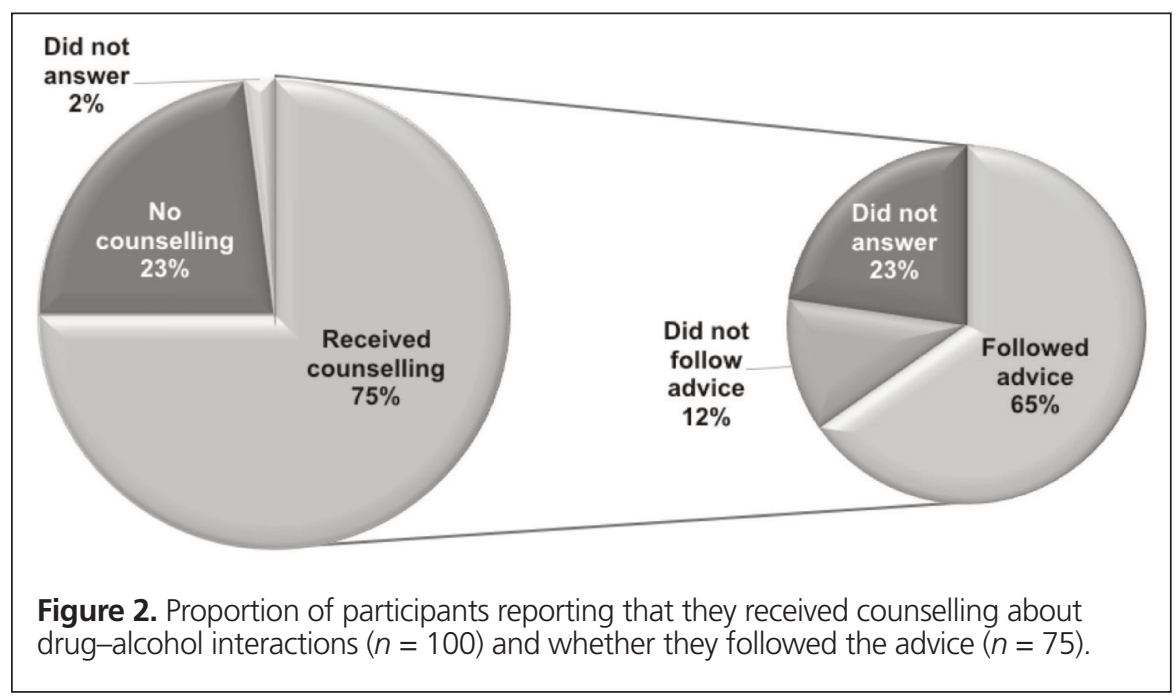



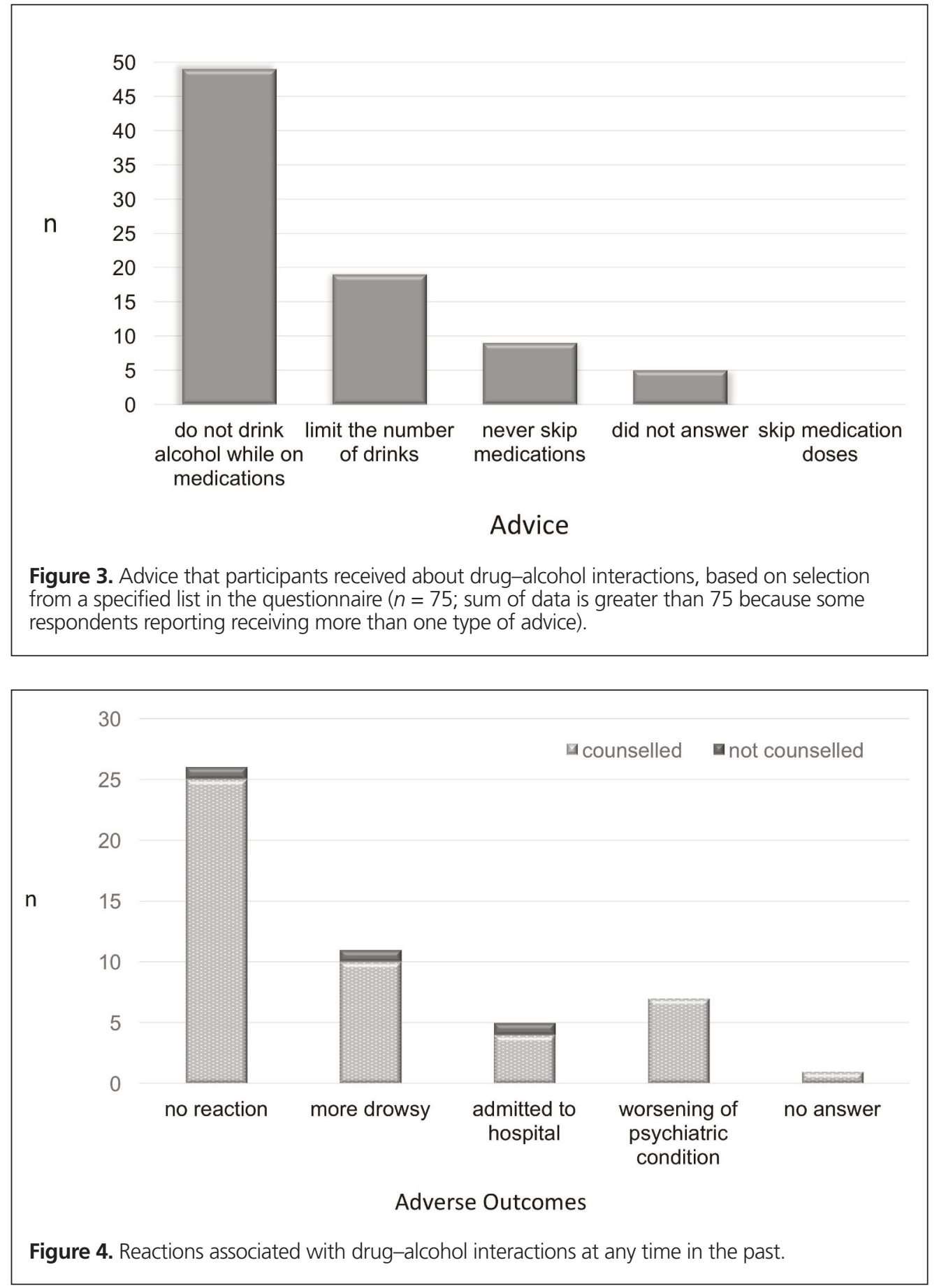

\section{DISCUSSION}

About a quarter of patients newly admitted to the Day Hospital Program participated in this survey. The participants were primarily young adults under the age of 40 , with about equal representation of men and women. Although the questionnaire was not designed to collect information about participants' psychiatric diagnoses, the majority reported having taken benzodiazepines or antidepressants (or both). About three- quarters of the study sample admitted to consuming alcohol at least occasionally, which is similar to the pattern of social drinking reported by Health Canada for 2012, whereby $78.4 \%$ of respondents stated having had at least one drink in the past year. ${ }^{11}$

A large proportion of participants $(75 \%)$ recalled being counselled about drug-alcohol interactions. This finding contrasts with a previous study, which reported that only $15.7 \%$ of US adults had ever discussed alcohol use with a health professional. ${ }^{12}$ This difference might be attributable to the populations studied: 


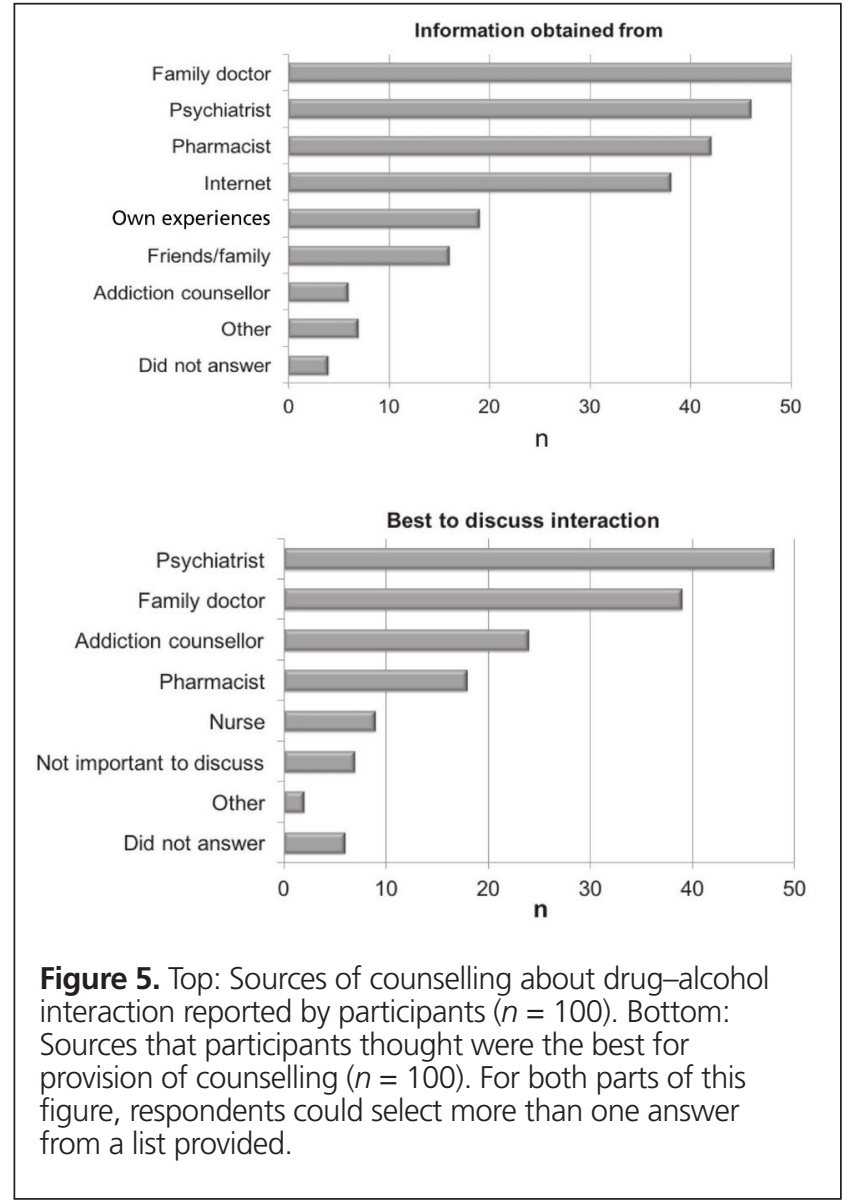

perhaps more emphasis is placed on drug-alcohol interactions during counselling about mental health medications than is the case for other medications for chronic conditions.

At present, there is no consensus on how clinicians should counsel patients on potential interactions between alcohol and psychotropic medications. Most patients in this study reported being advised not to drink alcohol while taking psychotropic medications or to limit the amount of alcohol consumed, consistent with recommendations in product monographs and standard drug references. Although the majority of respondents considered this information to be sufficient, some participants admitted not following this advice. More importantly, about a quarter of all respondents reported perceived harm as a result of a drug-alcohol interaction, including serious consequences such as hospital admission and worsening of their psychiatric conditions. The current study did not explore reasons why participants did not follow advice from health care professionals, but we hypothesize the following: challenges associated with avoiding alcohol completely when taking an interacting medication for a chronic condition, lack of a strong therapeutic alliance between the provider and patient, ${ }^{13}$ inadequate health literacy, insufficient time for proper counselling, and emotional barriers involving selfmedication. Future studies should explore these hypotheses to gain further insight on how adverse outcomes from drugalcohol interactions can be minimized.

With respect to the health care professionals that the patients thought would be best to discuss alcohol use and psychotropic medications, psychiatrists and family physicians received top rankings, followed by addiction counsellors and pharmacists. It was unclear why pharmacists were not considered best suited to provide drug interaction information in this population. Further studies should explore mental health patients' perceptions of various health care professionals in providing drug interaction advice.

This study had several limitations. It relied on self-reporting by participants, and previous studies have shown that individuals often under-report the amount of alcohol consumed when they are asked to self-report. ${ }^{14}$ Only about $25 \%$ of the patients newly admitted to the Day Hospital Program chose to participate in this study, which could have resulted in selection bias. A literature search revealed no previous questionnaires examining the use of alcohol by patients who were taking medications, so a new questionnaire was created to gather self-reported data and comments for this study; however, this questionnaire has not been validated. Although the readability of the questionnaire was evaluated by non-health care professionals, it was not pretested with individuals similar to the intended study sample. Some patients may have found the questionnaire difficult to navigate, and 31 questionnaires were excluded from the analysis because 3 or more questions had been left unanswered. For future studies, methods should be employed to ensure completion of the survey, such as use of electronic questionnaires or interviewers. This survey did not explore the temporal relationship between a patient's behaviour and the timing of counselling, nor was there any direct evidence of the type of counselling provided by clinicians. Finally, all participants were from the outpatient psychiatric day hospital program at a single site, which limits the generalizability of results to other patient groups.

\section{CONCLUSION}

Most of the participants in this study, drawn from patients attending the Adult Mental Health Day Hospital Program at North York General Hospital, reported having received information about alcohol-drug interactions from a health care provider. Nevertheless, some participants consumed alcohol and medications concurrently, and perceived that alcohol-drug interactions had caused them harm. The study results suggest that there may be a gap between professionals' recommendations and patients' behaviour. Future studies should explore which strategies can best minimize adverse consequences resulting from alcoholdrug interactions.

\section{References}

1. Thomas G. Alcohol Price Policy Series, Report 1 of 3: Levels and patterns of alcohol use in Canada. Ottawa (ON): Canadian Centre on Substance Abuse; 2012 [cited 2016 Aug 28]. Available from: www.ccsa.ca/Resource\%20 Library/CCSA-Patterns-Alcohol-Use-Policy-Canada-2012-en.pdf 
2. Weathermon R, Crabb DW. Alcohol and medication interactions. Alcohol Res Health. 1999;23(1):40-54.

3. Holder HD. Effects of alcohol, alone and in combination with medications. Walnut Creek (CA): Prevention Research Center; 1992.

4. Adam WL. Potential for adverse drug-alcohol interactions among retirement community residents. J Am Geriatr Soc. 1995;43(9):1021-5.

5. Forster LE, Pollow R, Stoller EP. Alcohol use and potential risk for alcoholrelated adverse drug reactions among community-based elderly. J Community Health. 1993;18(4):225-39.

6. Jalbert JJ, Quilliam BJ, Lapane KL. A profile of concurrent alcohol and alcohol-interactive prescription drug use in the US population. J Gen Intern Med. 2008;23(9):1318-23.

7. Pringle KE, Ahern FM, Heller DA, Gold CH, Brown TV. Potential for alcohol and prescription drug interactions in older people. J Am Geriatr Soc. 2005;53(11):1930-6.

8. Breslow RA, Dong C, White A. Prevalence of alcohol-interactive prescription medication use among current drinkers: United States, 1999-2010. Alochol Clin Exp Res. 2015;39(2):371-9.

9. Veldhuizen S, Wade TJ, Cairney J. Alcohol consumption among Canadians taking benzodiazepines and related drugs. Pharmacoepidemiol Drug Saf. 2009;18(3):203-10.

10. Partial hospitalization program. Toronto $(\mathrm{ON})$ : North York General Hospital; 2016 [cited 2016 Jul 27]. Available from: www.nygh.on.ca/ Default.aspx?cid=1205\&lang=1

11. Canadian alcohol and drug use monitoring survey. Ottawa $(\mathrm{ON})$ : Health Canada; 2014 [cited 2016 Jul 28]. Available from: www.hc-sc.gc.ca/ hc-ps/drugs-drogues/stat/2012/summary-sommaire-eng.php

12. McKnight-Eily LR, Liu Y, Brewer RD, Kanny D, Lu H, Denny CH, et al. Vital signs: communication between health professionals and their patients about alcohol use - 44 states and the District of Columbia, 2011. MMWR. 2014;63(1):16-22.

13. Levesque A, Li HZ, Pahal JS. Factors related to patients' adherence to medication and lifestyle change recommendations: data from Canada. Int J Psychol Stud. 2012;4(2):42-55.
14. Monk RL, Heim D, Qureshi A, Price A. "I have no clue what I drunk last night" using smartphone technology to compare in-vivo and retrospective self-reports of alcohol consumption. PLoS One. 2015;10(5):e0126209.

Cynthia Cheng, BSCPhm, PharmD, BCPS, RPh, is with North York General Hospital and the Leslie Dan Faculty of Pharmacy, University of Toronto, Toronto, Ontario.

Fatima Mithoowani, BScPhm, RPh, is with North York General Hospital, Toronto, Ontario.

Thomas Ungar, MD, MEd, CCFP, FCFP, FRCPC, DABPN, is with the Faculty of Medicine, University of Toronto, and St Michael's Hospital, Toronto, Ontario.

Monica Lee, BScPhm, MSc, PharmD, RPh, is with North York General Hospital and the Leslie Dan Faculty of Pharmacy, University of Toronto, Toronto, Ontario.

Competing interests: None declared.

Address correspondence to:

Dr Cynthia Cheng

Pharmacy Department

North York General Hospital

4001 Leslie Street

Toronto ON M2K 1E1

e-mail: cynthia.cheng@nygh.on.ca

Funding: None received.

Acknowledgement: The authors are grateful for presubmission review of this manuscript by Dr S Kalkar.

\section{ON THE FRONT COVER}

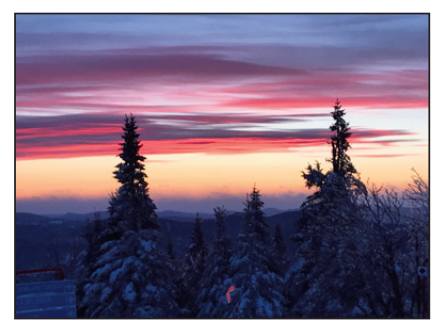

Mont Sainte-

Anne Beaupré, Quebec

This winter landscape shot was taken in early March atop Mont Sainte-Anne, the highest ski peak in eastern Canada. CSHP member François Cauchon, the President and CEO of BCE Pharma, used an iPhone 7 to take the photo.

The CJHP would be pleased to consider photographs featuring Canadian scenery taken by CSHP members for use on the front cover of the Journal. If you would like to submit a photograph, please send an electronic copy (minimum resolution $300 \mathrm{dpi}$ ) to publications@cshp.ca. 